\title{
Feasibility, effectiveness, and satisfaction achieved by the transdisciplinary intervention of a clinical-hospital ethics committee. A qualitative and quantitative study
}

\author{
Jorge O. Selandaria (D), Manuela de la Portilla ${ }^{a}$ (D) , M. Susana Ciruzzia (D), \\ Claudia Couceiro ${ }^{a}$ (D), Hernán O. García ${ }^{a}$ (D), M. de los Ángeles Iervolino ${ }^{a}$ (D), \\ Daniela N. Marin ${ }^{a}$ (D), Carina Miranda ${ }^{a}$ (D) Luis Novalia (D) Laura Ortega $a^{a}$ (D), \\ Corina Ponce $^{a}$ (D), Pablo Puccar ${ }^{\text {(D) }}$, Susana G. Quintana ${ }^{\text {(D) Estela Rodríguez }}$ (D), \\ Fernanda Ledesma ${ }^{a}$ (D)
}

\begin{abstract}
Introduction. A clinical ethics committee (CEC) haseducational, regulatory, advisory, mediation, and reflexive functions. As any health care service, the consults with the CEC should be subjected to review and quality improvement. The study objectives were to assess the feasibility, effectiveness, and satisfaction with the bioethical recommendations made by the CEC and assess their impact on the treating team and the patient's family.

Population and methods. Descriptive, retrospective, qualitative, and quantitative study of clinical cases submitted to the hospital's CEC between January $1^{\text {st }}, 2013$ and December 31 $1^{\text {st }}, 2017$ using data from the CEC minute book, medical records, registries from the Office for Remote Communication, and semi-structured interviews with health care team members.

Results. A total of 108 cases (106 patients) were analyzed: 73 cases with survey and registries and 35 with registries only. The main most frequent reasons for consultation were adequacy of therapeutic effort $(46 / 42.6 \%)$, severe neurological involvement $(15 / 13.9 \%)$, patient's quality of life $(11 / 10.2 \%)$, patient-family-health system conflict $(7 / 6.5 \%)$, and family's refusal of treatment $(6 / 5.6 \%)$.
\end{abstract}

a. Hospital de Pediatría S.A.M.I.C. Prof. Dr. Juan P. Garrahan, Autonomous City of Buenos Aires, Argentina.

E-mail address: Jorge O. Selandari: jselandari@intramed.net

Funding:

Research fellowship granted by Hospital de Pediatría S.A.M.I.C. Prof. Dr. Juan P.

Garrahan.

Conflict of interest:

None.

Received: 11-26-2020

Accepted: 8-5-2021
To cite: Selandari JO, de la Portilla M, Ciruzzi MS Couceiro $\mathrm{C}$, et al. Feasibility, effectiveness, and satisfaction achieved by the transdisciplinary intervention of a clinical-hospital ethics committee. A qualitative and quantitative study. Arch Argent Pediatr 2022;120(1):30-38.

\section{INTRODUCTION}

A clinical ethics committee (CEC) has educational, regulatory, advisory, mediation, and reflexive functions, among others. ${ }^{1}$ In relation to the latter 3 functions, as with any health care service, any consultation with the CEC regarding an individual case should be subjected to review and quality improvement..$^{2-8}$ However, the fundamental differences with clinical care services make the evaluation of the excellence and quality of clinical ethics consultations problematic and intricate. It is possible that for these reasons the investigation of these aspects is infrequent. ${ }^{9-11}$ For this reason, research about these aspects may be uncommon.

The objectives of this study were to assess the feasibility, effectiveness, and satisfaction of recommendations made by the CEC in ethical and health care-related problems and also assess their impact on the treating team and the patients' family.

\section{POPULATION AND METHODS}

This was a descriptive, retrospective, qualitative and quantitative study about clinical cases submitted to the hospital's CEC between January 1 $1^{\text {st }}, 2013$ and December $31^{\text {st }}, 2017$. It was based 
on data collected from the CEC minute book, medical records (MR), registries from the Office for Remote Communication (ORC), and semistructured interviews with health care team members involved in patient presentation. If the MR could not be obtained, the case was excluded.

MR items that had a subjective outcome were agreed upon among investigators and classified as per a 3-point Likert scale (not at all, partially, and completely).

One of the authors (MDLP) conducted interviews with the treating team, either in person or via telephone or email if the consult came from another institution.

Subjective items in the survey administered to health care providers were collected based on a 5-point Likert scale (see Annex: survey form and operationalization of variables). To facilitate reporting, these results were grouped into 3 categories: unfavorable and favorable, as end categories, and partial, as central category. In relation to reasons for consultation, survey respondents had a list of options from which they had to select the primary and other secondary reasons and, at the end, they could $\mathrm{w}$ rite additional reasons. If no survey was available for a specific case, the primary and secondary reasons were attributed based on registry analysis.

To facilitate communication, variables were classified into 3 groups: feasibility, effectiveness, and satisfaction (FES).

The anonymity of assessed cases and interviewed health care providers was warranted using conventional methods.

The informed consent was obtained orally. Data collection and analysis were done using REDCap $^{\circledR}$, Excel $^{\circledR}$, and conventional descriptive statistical methods.

The study was approved by the Research and Teaching Board of Hospital de Pediatría S.A.M.I.C. Prof. Dr. Juan P. Garrahan.

\section{RESULTS}

Out of 122 cases, 14 were excluded due to missing data, isolated request for drug authorization or brief consultations resolved by a CEC member.

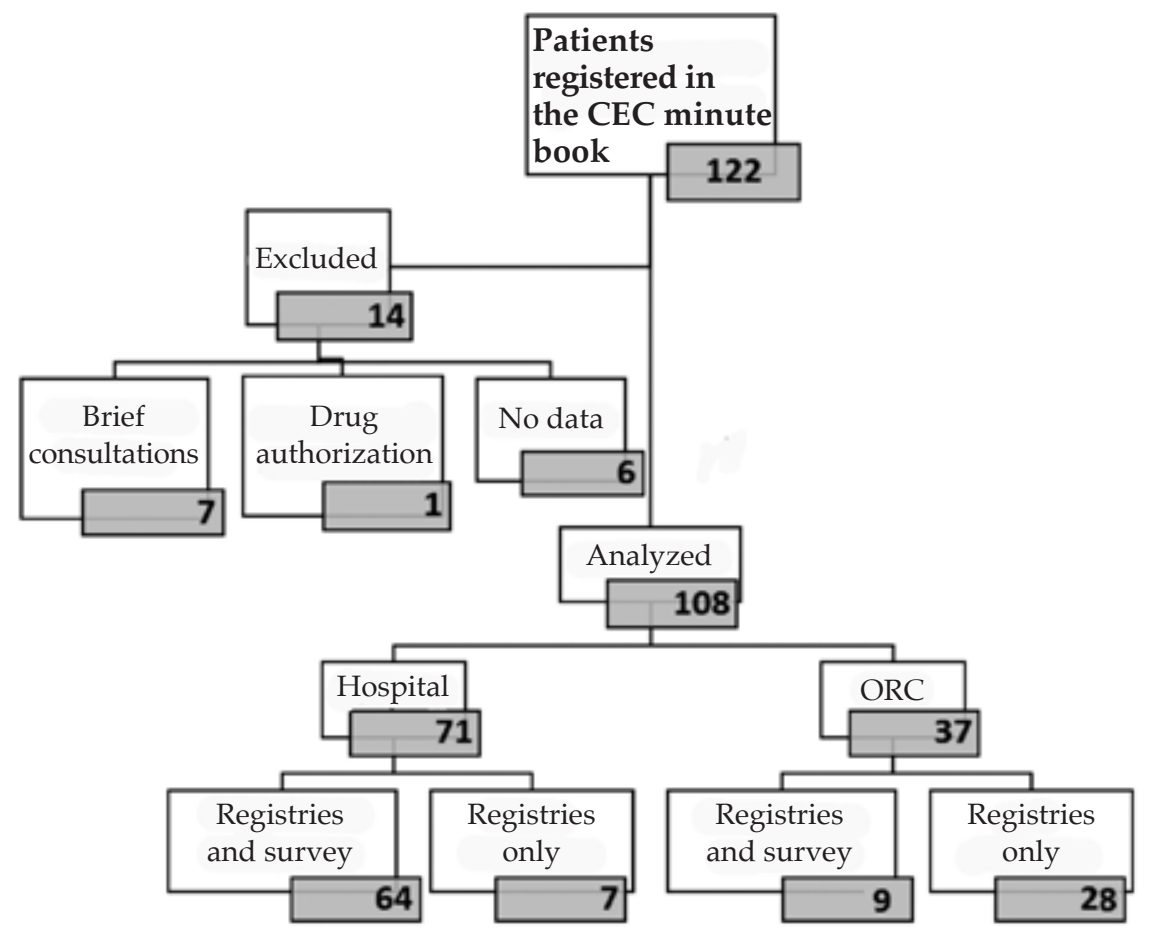

ORC: Office for Remote Communication. 
The final analysis included 108 cases (106 patients): 73 cases with survey and registries and 35 with registries only (MR, CEC minute book, and ORC) (Figure 1). Case distribution by year is regular; this and patient demographic data are shown in Table 1.

The main most frequent reasons for consultation were as follows (n/\%): adequacy of therapeutic effort $(46 / 42.6 \%)$, severe neurological involvement (15/13.9\%), patient's quality of life $(11 / 10.2 \%)$, patient-family-health system conflict $(7 / 6.5 \%)$, and family's refusal of treatment $(6 / 5.6 \%)$. All primary reasons for consultation are shown in Figure 2 whereas grouped primary and secondary reasons are seen in Figure 3 (see electronic Annex).

The number of meetings per case was a median of 1 (range: 1-5); 20 (19\%) had an urgent nature. In only 1 case, the CEC recommended a legal intervention on its own and, in 4 cases, it recommended the intervention of agencies for the protection of the rights of children and adolescents.

Table 2 shows a non-comprehensive list of the specialties participating in consultations with the CEC (see electronic Annex).

In all cases, a report to consultants was made with written recommendations; however, only in $31(28.7 \%)$, such report was included in the MR. In addition to these 31 cases, in $19(17.6 \%)$, a health care provider made a partial transcription in the
MR. That is to say, in only 50 of 108 cases (46.3\%) the consultation with the CEC had been registered in the MR.

\section{Profile and opinions of interviewed health care providers}

A total of 73 health care providers $(69.4 \%)$ completed the survey; 54 were females $(73.9 \%)$,

TABLE 1. Consultations per year and demographic data

\begin{tabular}{lc}
\hline Year & $\begin{array}{c}\text { Consultations } \\
\mathbf{n}(\%)\end{array}$ \\
\hline 2013 & $18(16.7)$ \\
2014 & $21(19.4)$ \\
2015 & $23(21.3)$ \\
2016 & $24(22.2)$ \\
2017 & $22(20.4)$ \\
\hline
\end{tabular}

\begin{tabular}{lc}
\hline Demographic data & \\
Sex & \\
Male & $62(58)$ \\
Female & $43(41)$ \\
Intersex & $1(1)$ \\
\hline Age & \\
Neonate & $2(1.9)$ \\
1-24 months old & $42(38.8)$ \\
$2-13$ years old & $47(43.5)$ \\
13-15 years old & $6(5.6)$ \\
$>16$ years old & $10(9.3)$ \\
No data for age & $1(0.9)$ \\
\hline
\end{tabular}

n: number.

Figure 2. Primary reasons for consultation

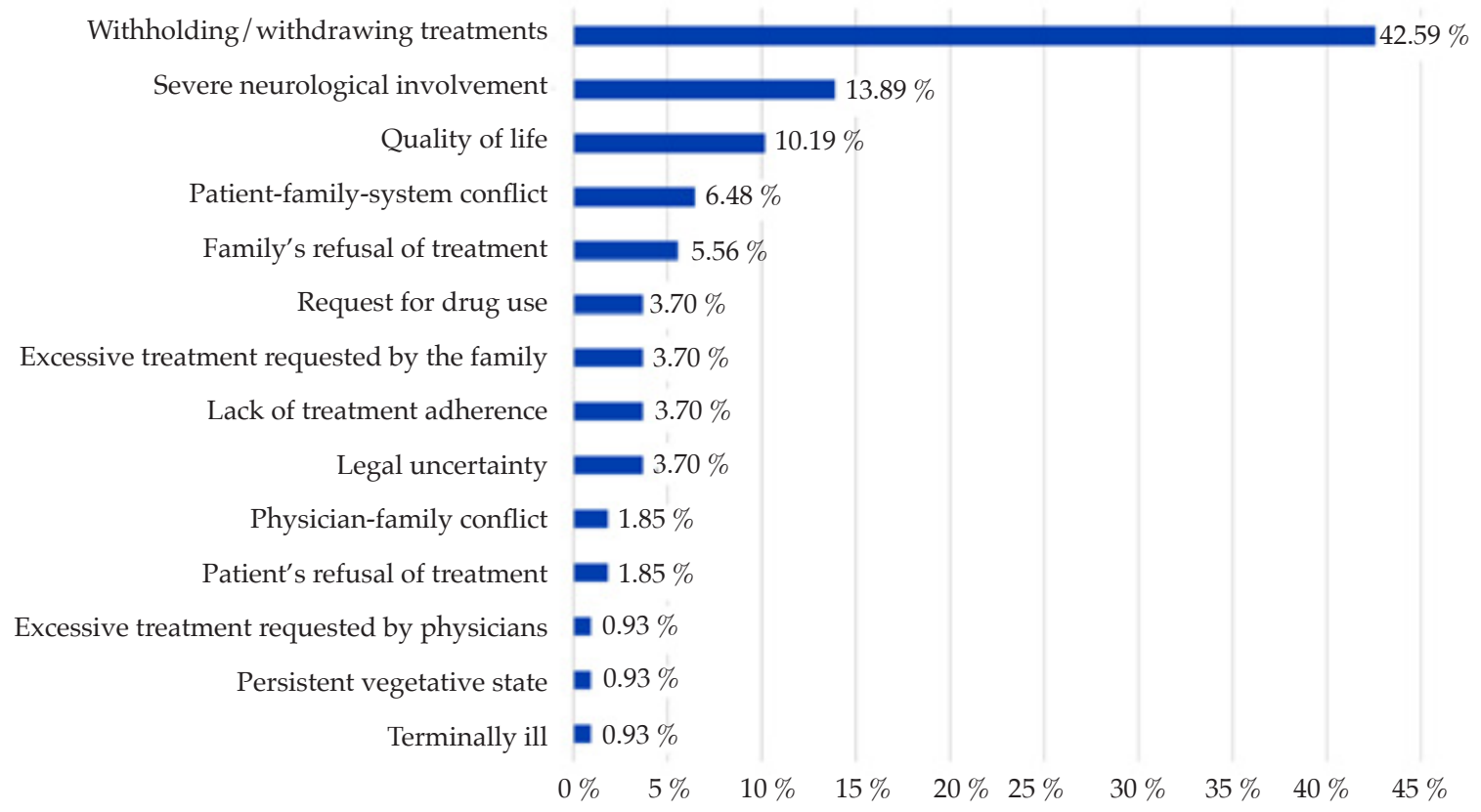


their mean (range) age was 49 years (35-63), and had a mean (range) professional experience of 12 years (4-40). Specialties and some of their areas of expertise are detailed in Table 3 (see electronic Annex). In some cases no survey was obtained because it was not possible to contact the treating team (29), the team member refused to be interviewed or did not recall the case (6).

In 46 cases $(64 \%)$, health care providers did not change their initial opinion; in $16(22 \%)$, they changed it partially; and in 10 (14\%), they modified it. In addition, 58 health care providers $(80 \%)$ stated that the consultation with the CEC increased their competence to approach difficult cases; 10 (14\%), that it had done so partially; and $5(6 \%)$, that it did not.

In relation to the consultation helping to clear legal questions, 38 health care providers $(52 \%)$ said it was helpful; $15(21 \%)$ that it was partially helpful; and $20(27 \%)$, that it did not help at all.

The results classified into feasibility, effectiveness, and satisfaction are summarized below. They are detailed in Table 4 .

\section{Feasibility}

Among survey respondents, 63 (86\%) considered that the CEC's suggestions were made in a timely manner to take decisions with the patient; and $60(82 \%)$, that the consultation with the CEC facilitated an adequate decision-making process by the health care team. In relation to the implementation of such decisions, $54(74 \%)$ believed that they were facilitated.

Consistency between the conduct and the recommendation could be assessed in 59 cases $(54.6 \%)$. The recommendation was fully adhered to in 50 cases $(85 \%)$.

\section{Effectiveness}

In relation to the CEC's recommendation having a positive impact on the patient or their family, 31 health care providers $(44 \%)$ stated that it did. According to 68 survey respondents $(93 \%)$, the consultation with the CEC did not worsen the situation.

Among the 108 analyzed cases, consistency between the actual and the expected course could be evaluated in $55(50.9 \%)$, with total or partial consistency in 47 (91\%).

\section{Satisfaction}

In total, 69 health care providers (95\%) agreed with the CEC's recommendation. In relation to the time devoted to preparing and conducting the consultation, 71 survey respondents (97\%) considered it was justified; and $70(96 \%)$ believed the consultation with the CEC was an overall positive experience.

The remarks noted in 38/73 surveys (52\%) are grouped by topic in Table 5 (see electronic Annex).

\section{DISCUSSION}

Few studies, either in adult or pediatric patients, have been found to be used in a comparison with our results. Table 6 shows a summary of the results of this study compared to the bibliography. ${ }^{12-24}$

Quality indicators are usually classified into structure, process, and result. ${ }^{25} \mathrm{~B}$ ased on such logic, the findings classified as FES (feasibility, effectiveness, and satisfaction) are result indicators of a consultation regarding an ethical issue. Quantifying the results of an ethical consultation is difficult; so much so that whether results or only structures and processes should be assessed during an ethical consultation is still a matter of debate. ${ }^{8,26,27}$ Therefore, it may be incorrect to assess a CEC based on feasibility, effectiveness, and satisfaction criteria. The characteristics mentioned here may not be considered CEC objectives; instead, its function is to provide adequate or good recommendations based on a solid and fair ethical reasoning. ${ }^{22}$

If a recommendation is the most adequate one, feasibility, satisfaction, etc. may be of little importance. However, it is easy to imagine scenarios where the CEC may make correct recommendations from an ethical perspective, but that the treating team does not implement, not because the recommendation is wrong but because the team fails. Also, ethically perfect recommendations may not be satisfactory for the treating team. On the other side, a CEC may arrive to an ethically correct argument, but make the wrong recommendations if the treating team has not performed an accurate technical and medical assessment of diagnoses, therapeutic options, and prognostic probabilities.

Therefore, it is not enough to make correct recommendations, since a main objective of the CEC is that the correct decision happens in the patient. If this is not the case, the failure may still be attributed to the CEC in terms of its main functions, such as creating consensus, interceding, managing knowledge, and having an inquisitive behavior regarding clinical possibilities.

In the CEC-treating team dyad, whose purpose is to reach an agreement about the decision that 
best respects the patient's and their family's values, in practice, "who is wrong" results insignificant. What really matters is that both parties should not overlook their shared objective and always seek ongoing improvement.

From another perspective, Mercurio ${ }^{2}$ addresses the problem of quantifying the performance of a CEC by matching it to the "satisfaction of the treating team and/or the patient's family", ${ }^{15}$ an argument also supported by Delany and Hall. ${ }^{28}$ We have already analyzed some of the weaknesses of equate satisfaction with performance, in addition to those described by other authors. ${ }^{6}$ Another risk of looking to satisfy the treating team is that of turning the CEC into just one more instrument of the hospital, one that has the power of persuasion over the patient and their family, for something similar to the cultural imperialism described by DeMichelis. ${ }^{29}$

Another effectiveness measure proposed for CECs is reducing both the length of stay in the intensive care unit (ICU) and life-sustaining treatments provided to patients who do not survive, addressed by Schneiderman et al. in

TABLE 4. Feasibility, effectiveness, and satisfaction

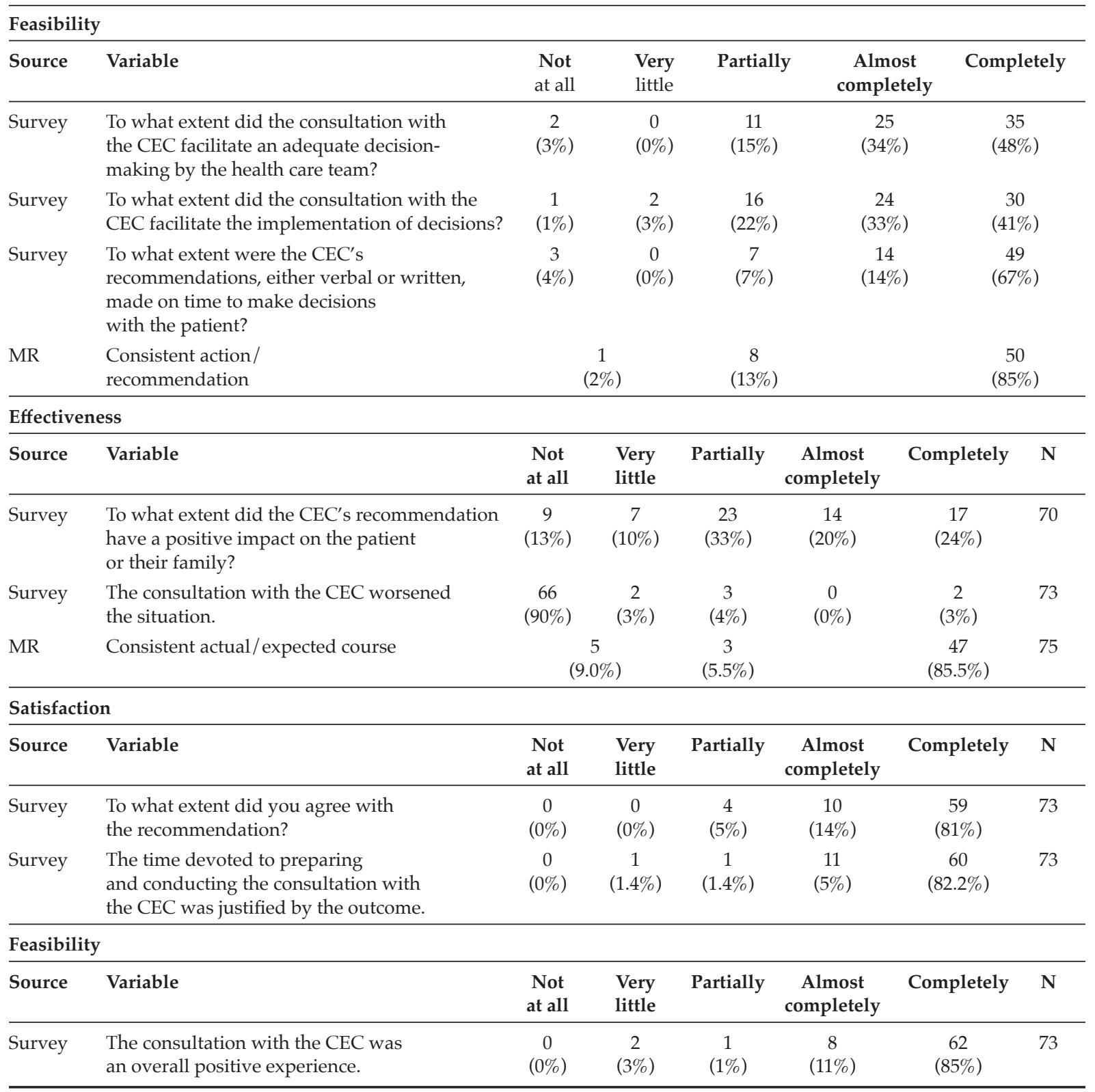

MR: medical record; CEC: clinical ethics committee. 


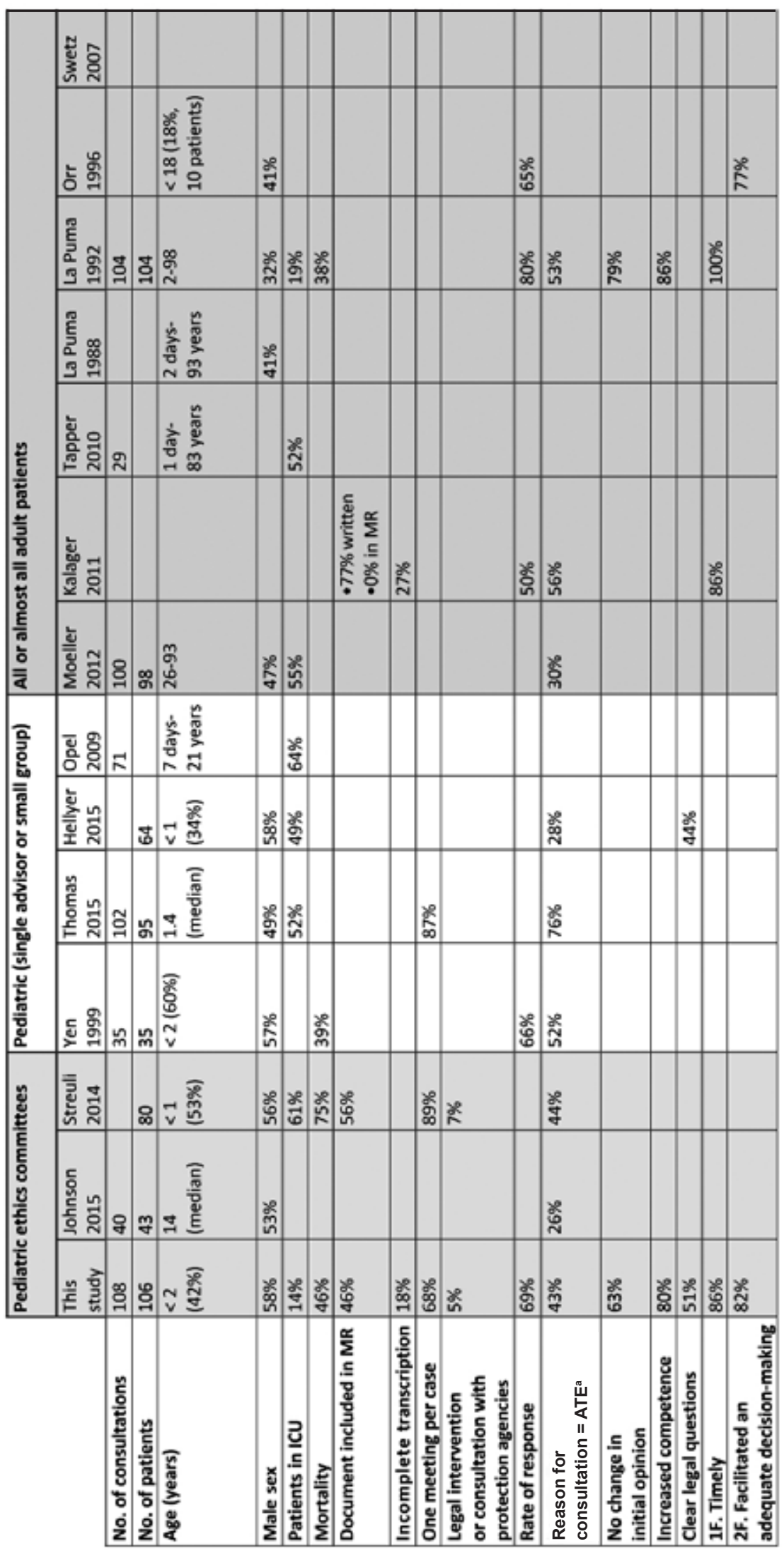



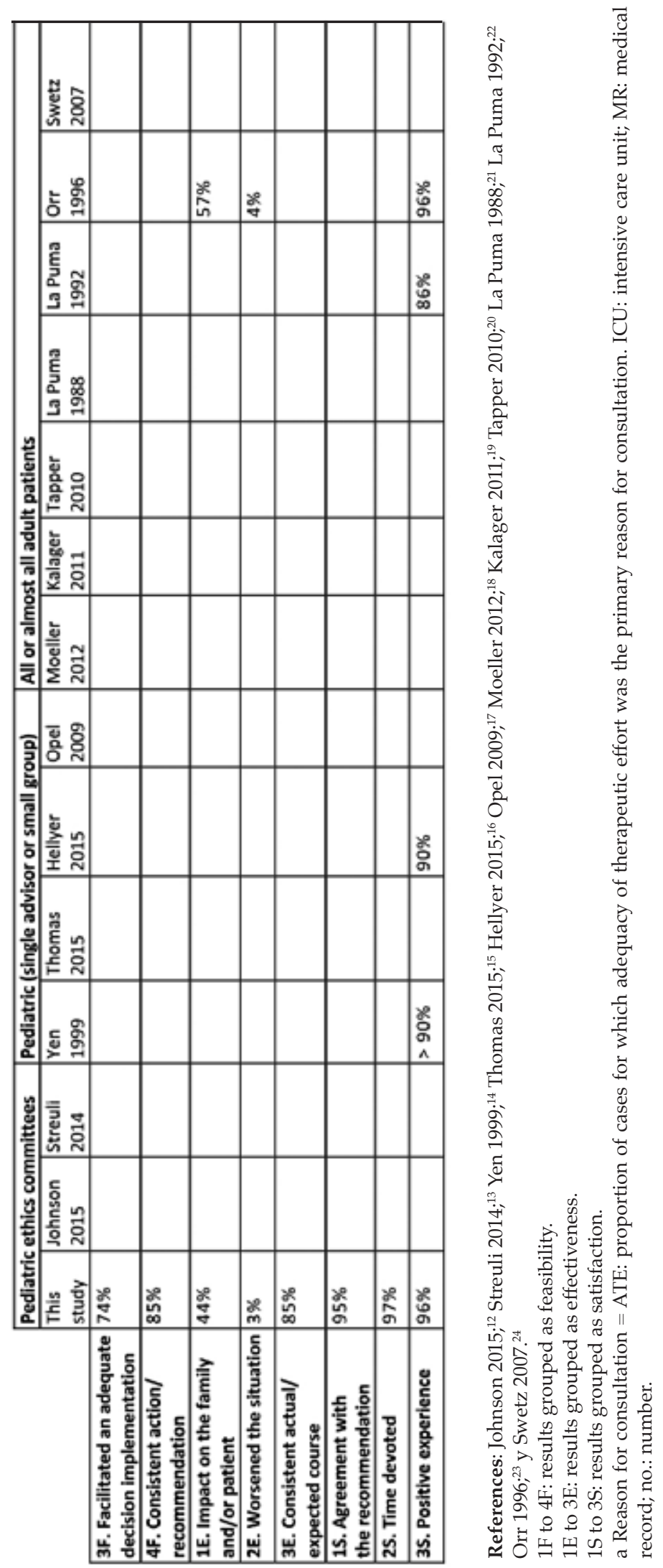
2 studies. ${ }^{30,31}$ This second outcome measure entails a suspected bias, sometimes referred to as the "self-fulfilling prophecy". It is logical to believe that, if life sustaining care is reduced, survival in the ICU will also reduce. Therefore, based on these data only, it is not possible to conclude that such reduction would have been correct, excessive or insufficient.

Examples of self-fulfilling prophecies give substance to such objection and include both individual cases and systematic actions. Austin et al. described the case of a patient with an extremely poor prognosis, where the health care team and her family agreed to stop her vital support, a decision that was delayed only a few days to allow family members to arrive from a distant location. Such delay allowed the patient to fully recover and demonstrate that her prognosis had been mistaken. ${ }^{32}$ Green et al. described the systematic decision of extracorporeal membrane oxygenation weaning due to lung failure after 5-14 days in patients with similar clinical characteristics in whom it was later verified that would have been able to survive if support had been prolonged. ${ }^{33}$ Becker et al., in their study of a prognostic model of intracranial hemorrhage, describe how the decision to withdraw the patient from vital support and a pessimistic attitude have a greater impact on decision-making than other objective factors, such as the extent of the hemorrhage or the Glasgow score. ${ }^{34}$ Ferrand and Racine, in a recent study, analyzed the difficulties faced by the health care team to make decisions based on prognosis, which reinforces the need to keep a humble attitude and an open mind during discussions based on prognostic estimations. ${ }^{35}$

In relation to taxonomy (feasibility, effectiveness, and satisfaction), it is not expected to be universally accepted because its use is clearly arguable. For example, feasibility items may be interpreted as corresponding to satisfaction ("the recommendations were made on time") or effectiveness ("facilitated the implementation", "consistency between actions and recommendations"). Like many other classifications, this is only an attempt to make the analysis of intricate and diffuse topics easier to understand.

Other limitations of this study are related to the methodology used. A large part of the information collected here was obtained from the answers of interviewed providers, which may be biased. Individually, interviewed people may bend their answers towards politeness due to their desire, conscious or unconscious, to be liked or to be respectful with the hospital. On the contrary, the same answers may be affected by a negative bias. It is not possible to rule out or establish the tendency of such bias or o nor any other bias entailed by survey methods.

Unlike other investigations, ${ }^{15,24,36}$ this study addressed the patients' and families' experience through the opinion of the treating team. At no time was their experience addressed directly. Although it is always made clear that the CEC is available for any need stated by the family, both in the written recommendations and the meetings with the treating team, such request is seldom made. This is possibly because, since its origin, Hospital Garrahan's CEC was established as an advisory body for the treating team and is the target of such efforts. In most cases, the treating team has a strong bond with the patient and their family, so the CEC's interference in such physician-patient relationship may be seen as a disadvantage that could lead to adverse effects or dissatisfaction. ${ }^{15,37}$ When the treating team requests the CEC's help to provide the family with feedback about the meeting, 1 to 3 CEC members channel such request.

Other methodologies have been described to assess the performance of individual advisors, small groups or committees regarding ethical consultations, such as analyzing the CEC structure or the consultation process.,938 Structure assessments focus on components, certifications, and competences of CEC members. Other process analyses include, for example, the analysis of the written consultation report using a holistic instrument developed by Pearlman et al., ${ }^{39}$ or the checklists proposed by Flicker et al. ${ }^{40}$

Considering the limitations and problems mentioned in this study and by other authors, ${ }^{6,11,12}$ we deem the results of this investigation relevant. These are the initial steps in our hospital towards the implementation of ongoing improvement tools for the strengthening of the CEC processes.

\section{CONCLUSIONS}

This study revealed high levels of satisfaction $(>95 \%)$ and moderate levels of feasibility $(>74 \%)$ and effectiveness $(>85 \%)$. Among health care providers, $80 \%$ stated that the consultation with the CEC increased their competence to approach difficult cases and $51 \%$, that it helped to clear legal questions. However, only $44 \%$ considered that the consultation had a positive impact on the patient and their family. The study findings 
motivated improvements in the development of consultations with the CEC, especially in terms of documentation, communication during the consultation process, and reassessment of direct contact between parents and patients and the CEC.

\section{REFERENCES}

1. Rivera Montero R. Comités hospitalarios de bioética. In: Sepúlveda JA. Bioética en pediatría. México, D.F.: Manual Moderno; 2014.Pág.13.

2. Mercurio MR. Pediatric ethics committees. In: Miller G (ed). Pediatric Bioethics. Cambridge: Cambridge University Press; 2010.Págs.87-110.

3. Lo B. Behind closed doors. Promises and pitfalls of ethics committees. N Engl J Med. 1987; 317(1):46-50.

4. Craig JM, May T. Evaluating the outcomes of ethics consultation. J Clin Ethics. 2006; 17(2):168-80.

5. Williamson L. Empirical assessments of clinical ethics services: implications for clinical ethics committees. Clin Ethics. 2007; 2(4):187-92.

6. Slowther AM, Hope T. Clinical ethics committees. BMJ. 2000; 321(7262):649-50.

7. Au SS, Couillard P, des Ordons AR, Fiest KM, et al. Outcomes of Ethics Consultations in Adult ICUs: A Systematic Review and Meta-Analysis. Crit Care Med.2018; 46(5):799-808.

8. Aulisio MP, Arnold RM, Youngner SJ. Health care ethics consultation: nature, goals, and competencies. A position paper from the Society for Health and Human ValuesSociety for Bioethics Consultation Task Force on Standards for Bioethics Consultation. Ann Intern Med. 2000; 133(1):5969.

9. University of Toronto Joint Centre for Bioethics. Evaluating Excellence in Bioethics: a value for investment project, 2010. In University of Toronto Joint Centre for Bioethics Review. 2011:67-104. [Accessed on: August $5^{\text {th }}$, 2021]. Available at: http:/ / 128.100.72.105/about/documents / FINAL_UofT_ JCB_Review.pdf

10. Williamson L, McLean S, Connell J. Clinical ethics committees in the United Kingdom: towards evaluation. Med Law Int. 2007; 8(3):221-38.

11. RepenshekM. Continuous Quality Improvement Initiatives in Ethics: A Proposed Communication Tool. Health Care Ethics USA. 2012.Pages 2-12.

12. Johnson LM, Church CL, Metzger M, Baker JN. Ethics consultation in pediatrics: long-term experience from a pediatric oncology center. Am J Bioeth. 2015; 15(5):3-17.

13. Streuli JC, Staubli G, Pfändler-Poletti M, BaumannHölzle R, Ersch J. Five-year experience of clinical ethics consultations in a pediatric teaching hospital. Eur J Pediatr. 2014; 173(5):629-36.

14. Yen BM, Schneiderman LJ. Impact of pediatric ethics consultations on patients, families, social workers, and physicians. J Perinatol. 1999; 19(5):373-8.

15. Thomas SM, Ford PJ, Weise KL, Worley S, Kodish E. Notjust little adults: a review of 102 paediatric ethics consultations. Acta Paediatr. 2015; 104(5):529-34.

16. Henriksen Hellyer J, Schiltz B, Moon W, Grafelman M, et al. Pediatric clinical ethics consultations at an academic medical center: does one size fit all? Am J Bioeth. 2015; 15(5):20-4

17. OpelDJ, Wilfond BS, Brownstein D, DiekemaDS, Pearlman RA. Characterisation of organisational issues in paediatric clinical ethics consultation: a qualitative study. JMed Ethics. 2009; 35(8):477-82.

18. Moeller JR, Albanese TH, Garchar K, Aultman JM, et al. Functions and outcomes of a clinical medical ethics committee: a review of 100 consults. HEC Forum. 2012; 24(2):99-114.
19. Kalager G, Førde R, Pedersen R. Is the discussion of patient cases in clinical ethics-committees useful? Tidsskr Nor Laegeforen. 2011; 131(2):118-21.

20. Tapper EB, Vercler CJ, Cruze D, Sexson W. Ethics consultation at a large urban public teaching hospital. Mayo Clin Proc. 2010; 85(5):433-8.

21. LaPuma J, Stocking CB, Silverstein MD, DiMartini A, Siegler $M$. An ethics consultation service in a teaching hospital. Utilization and evaluation. JAMA. 1988; 260(6):808-11.

22. La Puma J, Stocking CB, Darling CM, Siegler M. Community hospital ethics consultation: evaluation and comparison with a university hospital service. Am J Med. 1992; 92(4):346-51.

23. Orr RD, Morton KR, deLeon DM, Fals JC. Evaluation of an ethics consultation service: patient and family perspective. Am J Med. 1996; 101(2):135-41.

24. Swetz KM, Crowley ME, Hook C, Mueller PS. Report of 255 clinical ethics consultations and review of the literature. Mayo Clin Proc. 2007; 82(6):686-91.

25. Donabedian A. The quality of care. How can it be assessed? JAMA. 1988; 260(12):1743-8.

26. Schildmann J, Nadolny S, HaltaufderheideJ, Vollmann J, et al. Measuring Outcomes of Ethics Consultation: Empirical and Ethical Challenges. Crit Care Med. 2019; 47(1):e67-8.

27. Au SS. The author replies. Crit Care Med. 2019; 47(1):e68.

28. Delany C, Hall G. 'I just love these sessions'. Should physician satisfaction matter in clinical ethics consultations? Clin Ethics. 2012; 7(3):116-21.

29. DeMichelis C. The Best Interests Standard as a Logic of Empire: Unpacking the Political Dimensions of Parental Refusal. Am I Bioeth. 2018; 18(8):83-5.

30. Schneiderman LJ, Gilmer T, Teetzel HD. Impact of ethics consultations in the intensive care setting: a randomized, controlled trial. Crit Care Med. 2000; 28(12):3920-4.

31. Schneiderman LJ, Gilmer T, Teetzel HD, Dugan DO, et al. Effect of ethics consultations on nonbeneficial lifesustaining treatments in the intensive care setting: a randomized controlled trial. JAMA. 2003; 290(9):1166-72.

32. Austin EB, Hobbs H, Crouse BA, Lobos AT. A case report of full recovery from severe cerebral edema secondary to acetaminophen-induced hepatotoxicity in a 13 year old girl. BMC Pediatr. 2018; 18(1):247.

33. Green TP, Moler FW, Goodman DM. Probability of survival after prolonged extracorporeal membrane oxygenation in pediatric patients with acute respiratory failure. Extracorporeal Life Support Organization. Crit Care Med. 1995; 23(6):1132-9.

34. Becker KJ, Baxter AB, Cohen WA, Bybee HM, et al. Withdrawal of support in intracerebral hemorrhage may lead to self-fulfilling prophecies. Neurology. 2001;56(6):76672.

35. Ferrand A, Racine E. Can Clinicians Be Objective? Inherent Challenges in Using Decision-Making Tools in Cases of Entrenched Disagreements. Am J Bioeth. 2018; 18(8):80-2.

36. McClung JA, Kamer RS, DeLuca M, Barber HJ. Evaluation of a medical ethics consultation service: opinions of patients and health care providers. Am J Med. 1996; 100(4):456-60.

37. Matheny Antommaria AH. Intensified Conflict Instead of Closure: Clinical Ethics Consultants' Recommendations' Potential to Exacerbate Ethical Conflicts. Am J Bioeth. 2015; 15(1):52-4.

38. Larcher V, Slowther AM, Watson AR, UK Clinical Ethics Network. Core competencies for clinical ethics committees. Clin Med (Lond). 2010; 10(1):30-3.

39. Pearlman RA, Foglia MB, Fox E, Cohen JH, et al. Ethics Consultation Quality Assessment Tool: A Novel Method for Assessing the Quality of Ethics Case Consultations Based on Written Records. Am J Bioeth. 2016; 16(3):3-14.

40. Flicker LS, Rose SL, Eves MM, Flamm AL, et al. Developing and testing a checklist to enhance quality in clinical ethics consultation. J Clin Ethics. 2014; 25(4):281-90. 


\section{ANNEX}

FIGURE 3. Grouped primary and secondary reasons

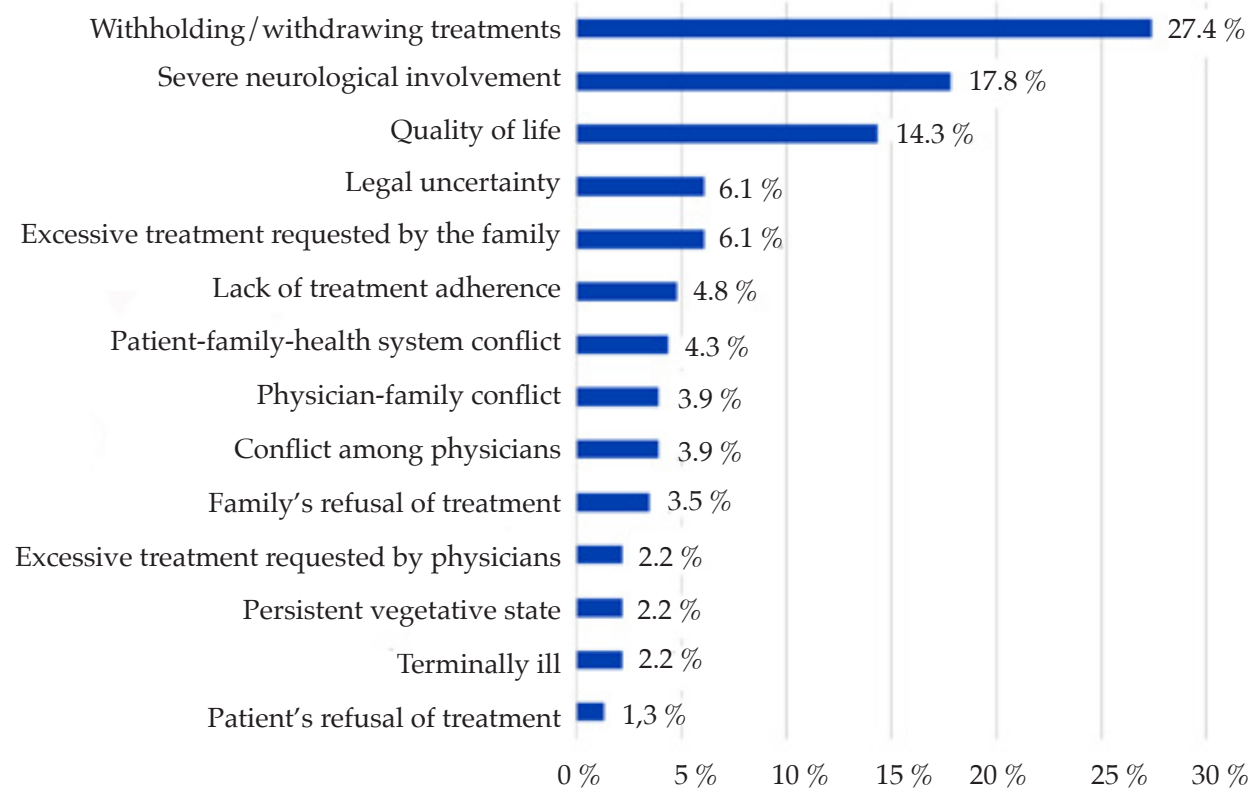

One or more reasons per case. Total $=230$ reasons in 108 cases.

TABLE 2. Specialties participating in consultations

\begin{tabular}{lcclcc}
\hline Specialty & $\mathbf{n}$ & $\%$ & Specialty & $\mathbf{n}$ & $\%$ \\
\hline 1. Mental health & 34 & 11.4 & 19. Traumatology and orthopedics & 5 & 1.7 \\
2. Palliative care & 32 & 10.7 & 20. Neonatology & 5 & 1.7 \\
3. Neurology & 32 & 10.7 & 21. Bioethics & 5 & 1.7 \\
4. Social services & 20 & 6.7 & 22. Cardiovascular surgery & 3 & 1 \\
5. Cardiology & 16 & 5.4 & 23. Plastic surgery and burn care & 3 & 1 \\
6. Hematology and oncology & 16 & 5.4 & 24. Dermatology & 3 & 1 \\
7. Neurosurgery & 15 & 5 & 25. Inborn errors of metabolism & 3 & 1 \\
8. Nephrology & 13 & 4.3 & 26. Spinal disease & 3 & 1 \\
9. Genetics & 12 & 4 & 27. Intensive care & 3 & 1 \\
10. Gastroenterology & 8 & 2.7 & 28. Bone marrow transplant & 3 & 1 \\
11. Pulmonology & 8 & 2.7 & 29. Radiology and interventional radiology & 3 & 1 \\
12. Pediatrics & 8 & 2.7 & 30. Interdisciplinary clinics & 2 & 0.7 \\
13. General surgery & 7 & 2.3 & 31. Respiratory endoscopy & 2 & 0.7 \\
14. Hepatology & 6 & 2 & 32. Hemotherapy & 2 & 0.7 \\
15. Growth and development & 5 & 1.7 & 33. Infectious diseases & 2 & 0.7 \\
16. Endocrinology & 5 & 1.7 & 34. Adolescence & 2 & 0.7 \\
17. Nutrition & 5 & 1.7 & 35 . Urology & 1 & 0.3 \\
18. Ophthalmology & 5 & 1.7 & 36. Imaging tests & 1 & 0.3 \\
\hline
\end{tabular}

n: number. 
TABLE 3. Professional specialty and area of expertise ${ }^{*}$ of interviewed providers

\begin{tabular}{|c|c|c|c|c|c|}
\hline Specialty and area of expertise & $\mathbf{n}$ & $\%$ & Specialty and area of expertise & $\mathbf{n}$ & $\%$ \\
\hline Clinical pediatrics & 22 & 30.14 & Palliative care & 3 & 4.11 \\
\hline General medicine & 13 & 17.81 & Neurology & 3 & 4.11 \\
\hline Hospitalization & 6 & 8.22 & Neuromuscular disease & 2 & 2.74 \\
\hline Emergency care & 2 & 2.74 & Epilepsy & 1 & 1.37 \\
\hline Complex chronic conditions & 1 & 1.37 & Growth and development & 2 & 2.74 \\
\hline Intensive care & 13 & 17.81 & Liver transplantation & 2 & 2.74 \\
\hline General intensive care & 12 & 16.44 & Ophthalmology & 2 & 2.74 \\
\hline Immunocompromised patients & 1 & 1.37 & Inborn errors of metabolism & 2 & 2.74 \\
\hline Nephrology & 7 & 9.59 & Social services & 1 & 1.37 \\
\hline Nephrology & 4 & 5.48 & Burn unit & 1 & 1.37 \\
\hline Renal transplantation & 3 & 4.11 & Neonatology & 1 & 1.37 \\
\hline Hematology and oncology & 7 & 9.59 & Radiology & 1 & 1.37 \\
\hline Non-malignant hematology & 1 & 1.37 & Interventional radiology & 1 & 1.37 \\
\hline Oncology & 6 & 8.22 & Physical therapy & 1 & 1.37 \\
\hline Mental Health & 5 & 6.85 & Pediatric physical therapy & 1 & 1.37 \\
\hline Psychology & 2 & 2.74 & & & \\
\hline Psychiatry & 2 & 2.74 & & & \\
\hline \multirow[t]{2}{*}{ Oncology } & 1 & 1.37 & & & \\
\hline & & & Overall total & 73 & 100 \\
\hline
\end{tabular}

n: number.

*Area of expertise referred by the interviewed provider.

TABLE 5. Remarks grouped by topic

\begin{tabular}{lcc}
\hline Topic & n & $\%$ \\
\hline Positive assessment of activity & 10 & 13.7 \\
Greater visibility of recommendations in medical records & 7 & 9.6 \\
Only verbal recommendations; written recommendations were delayed or were never received & 3 & 3.1 \\
Dissatisfaction with the CEC & 2 & 4.1 \\
Wished to follow-up on the case & 2 & 2.7 \\
More efficient recommendations & 2 & 2.7 \\
Proposed the CEC as an educational activity for young physicians and residents & 1 & 1.4 \\
Did not believe it was an unbiased recommendation & 1 & 1.4 \\
Complaint that the CEC's response is about how and not what & 1 \\
More objectivity. "The use of images during the presentation reduces the case objectivity. & 1 \\
It causes a higher impact on those who are not familiar with the patient and there is a & 1.4 \\
big difference between those who know them and those who don't". & 1 \\
More subjectivity. "I would suggest that the patient should be seen before making decisions to prevent & \\
patient depersonalization. The CEC should meet them, know the patient and the treating team". & 1.4 \\
Greater involvement of the CEC in decision communication & 1.4 \\
Felt overlooked by a CEC member & 1
\end{tabular}

CEC: clinical ethics committee; n.: number. 
Hospital de Pediatría S.A.M.I.C. "Prof. Dr. Juan P. Garrahan"

Sex:

Age:

Professional experience:

Main specialty:

Area of expertise:

Select the reason(s) for consultation with the clinical ethics committee (CEC)

(You may select several options; write " 1 " next to the main reason.)

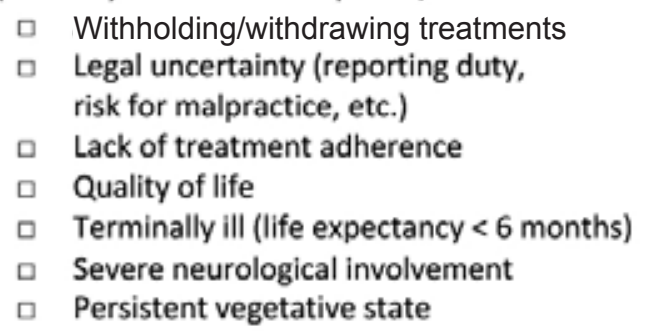

$\square$ Excessive treatment requested by physicians

$\square$ Excessive treatment requested by the family

ㄷ Family's refusal of treatment

口 Patient's refusal of treatment

Conflict among team physicians

ㅁ Health care team-family conflict

口 Patient-family-health system conflict (hospital, group health plan funded by a labor union, HMO plan, etc.)

$\square$ Other/s (write your remarks on the back)

Mark with an " $\mathrm{X}$ " the option that best suits your opinion.

\begin{tabular}{|c|c|c|c|c|c|}
\hline $\begin{array}{l}\text { 1. Not at all, 2. Very little, 3. Partially, 4. Almost completely, } \\
\text { 5. Completely }\end{array}$ & 1 & 2 & 3 & 4 & 5 \\
\hline \multicolumn{6}{|l|}{ To what extent did you agree with the recommendation? } \\
\hline \multicolumn{6}{|l|}{$\begin{array}{l}\text { To what extent did the consultation with the CEC facilitate } \\
\text { an adequate decision-making by the health care team? }\end{array}$} \\
\hline \multicolumn{6}{|l|}{$\begin{array}{l}\text { To what extent did the consultation with the CEC facilitate } \\
\text { the implementation of decisions? }\end{array}$} \\
\hline \multicolumn{6}{|l|}{$\begin{array}{l}\text { To what extent were the CEC's recommendations, either } \\
\text { verbal or written, made on time to make decisions with } \\
\text { the patient? }\end{array}$} \\
\hline \multicolumn{6}{|l|}{$\begin{array}{l}\text { To what extent did the consultation with the CEC change } \\
\text { your opinion about the case? }\end{array}$} \\
\hline $\begin{array}{l}\text { To what extent did the CEC's recommendation have } \\
\text { a positive impact on the patient or their family? }\end{array}$ & & & & & \\
\hline
\end{tabular}

\begin{tabular}{|c|c|c|c|c|c|}
\hline $\begin{array}{l}\text { 1. Strongly disagree, } 2 \text {. Disagree. } 3 . \text { Neither agree nor disagree, } \\
\text { 4. Agree, } 5 \text {. Strongly agree }\end{array}$ & 1 & 2 & 3 & 4 & 5 \\
\hline \multicolumn{6}{|l|}{$\begin{array}{l}\text { The time devoted to preparing and conducting the } \\
\text { consultation with the CEC was justified by the outcome. }\end{array}$} \\
\hline \multicolumn{6}{|l|}{ The consultation with the CEC worsened the situation. } \\
\hline \multicolumn{6}{|l|}{$\begin{array}{l}\text { The consultation with the CEC was an overall } \\
\text { positive experience. }\end{array}$} \\
\hline \multicolumn{6}{|l|}{ The consultation with the CEC helped to clear legal questions. } \\
\hline \multicolumn{6}{|l|}{$\begin{array}{l}\text { The consultation with the CEC increased your competence } \\
\text { to approach difficult cases. }\end{array}$} \\
\hline \multicolumn{6}{|l|}{ Write your remarks on the back. } \\
\hline
\end{tabular}


Remarks: 
Operationalization of variables collected in the record book

\begin{tabular}{|c|c|c|}
\hline Variable & Type & Operational definition \\
\hline Initial date of submission & Discrete quantitative & Date registered in CEC minute book \\
\hline Reason for submission & Nominal categorical & Explicit/implicit \\
\hline Diagnostic categorical & Nominal categorical & Specialty that initiated the consultation \\
\hline Other relevant specialties & Nominal categorical & Present during patient visit \\
\hline $\begin{array}{l}\text { Categorization of source of ethical issue or } \\
\text { problem with decision-making }\end{array}$ & Nominal categorical & List of options and free text \\
\hline Number of CEC meetings & Discrete quantitative & Count in CEC minute book \\
\hline Case for urgent resolution? & $\begin{array}{l}\text { Nominal dichotomous } \\
\text { categorical }\end{array}$ & $\begin{array}{l}\text { Case for which a decision is requested } \\
\text { necessary in a fixed time limit, less than } \\
7 \text { days: Yes / no }\end{array}$ \\
\hline Legal intervention? & $\begin{array}{l}\text { Nominal dichotomous } \\
\text { categorical }\end{array}$ & $\begin{array}{l}\text { Do the measures included in the report } \\
\text { suggest a legal intervention?: Yes/no }\end{array}$ \\
\hline $\begin{array}{l}\text { Intervention by other external agency for the } \\
\text { protection of the rights of children } \\
\text { and adolescents? }\end{array}$ & $\begin{array}{l}\text { Nominal dichotomous } \\
\text { categorical }\end{array}$ & $\begin{array}{l}\text { Do the measures included in the report } \\
\text { suggest an intervention by other external } \\
\text { agency for the protection of the rights of } \\
\text { children and adolescents?: Yes/no }\end{array}$ \\
\hline
\end{tabular}

Operationalization of variables collected in the medical record

\begin{tabular}{|c|c|c|}
\hline Variable & Type & Operational definition \\
\hline Does it include the recommendation document? & $\begin{array}{l}\text { Nominal dichotomous } \\
\text { categorical }\end{array}$ & Yes/no \\
\hline $\begin{array}{l}\text { If the recommendation document is not included, } \\
\text { was it transcribed into the clinical course sheet? }\end{array}$ & $\begin{array}{l}\text { Nominal dichotomous } \\
\text { categorical }\end{array}$ & Yes/no \\
\hline Transcription & $\begin{array}{l}\text { Nominal dichotomous } \\
\text { categorical }\end{array}$ & Total/partial \\
\hline Course & Nominal categorical & Live/dead/unknown \\
\hline Date of consultation with the CEC & Discrete quantitative & Date as per medical record \\
\hline Date of latest entry in the medical record & Discrete quantitative & $\begin{array}{l}\text { Date of latest description of course in the } \\
\text { medical record }\end{array}$ \\
\hline Follow-up duration & Continuous quantitative & Date of latest entry - date of consultation \\
\hline Date of death & Discrete quantitative & Date as per medical record \\
\hline Survival time & Continuous quantitative & Date of death and date of consultation \\
\hline Consistent action/recommendation & Ordinal categorical & $\begin{array}{l}\text { The actions recorded in the medical record } \\
\text { show that the recommendation was followed } \\
\text { Likert scale* }\end{array}$ \\
\hline Consistent actual/expected course & Ordinal categorical & $\begin{array}{l}\text { The patient course is consistent with that } \\
\text { presumed in the recommendation document } \\
\text { Likert scale* }\end{array}$ \\
\hline
\end{tabular}

${ }^{*}$ Descriptors 1 to 3: Not at all, partially, completely. Which were the primary reasons for consultation with the CEC? (More than 1 category may be applied to each case.) The interviewed provider will have the same options described under "Categorization of source of ethical issue or problem with decision-making" plus an empty field to specify and describe other reasons not provided in the examples.

The following variables will receive a subjective qualification by the interviewed provider in response to the statement "In your opinion..." using a 5-point Likert scale with the following descriptors, as applicable:

1) Strongly disagree, 2) disagree, 3) neither agree nor disagree, 4) agree, 5) strongly agree.

1) Not at all, 2) very little, 3) partially, 4) almost completely, 5) completely. 
Operationalization of variables collected in the interviews

\begin{tabular}{|c|c|c|}
\hline Variable & Type & Operational definition \\
\hline Nomir & inal dichotomous categorical & Male/female \\
\hline Age & Discrete quantitative & Years \\
\hline Professional experience & Discrete quantitative & Years \\
\hline Main specialty & Nominal categorical & Pediatrics or subspecialty \\
\hline Area of expertise & Nominal categorical & In relation to pediatrics or subspecialty \\
\hline Primary reasons for consultation & Nominal categorical & $\begin{array}{l}\text { Multiple selection of } 1 \text { or more options, indicating } \\
\text { primary reason + optional free text }\end{array}$ \\
\hline Time devoted & Ordinal categorical & $\begin{array}{l}\text { "The time devoted to preparing and conducting the } \\
\text { consultation with the CEC was justified by the } \\
\text { outcome". Likert scale* }\end{array}$ \\
\hline Timely & Ordinal categorical & $\begin{array}{l}\text { "The CEC's opinion/recommendations, either verbal or } \\
\text { written, were made on time to make decisions with the } \\
\text { patient". Likert scale\# }\end{array}$ \\
\hline Agreement with the recommendation & Ordinal categorical & $\begin{array}{l}\text { "Agreement with the recommendation". } \\
\text { Likert scale\# }\end{array}$ \\
\hline Facilitated an adequate decision-making & Ordinal categorical & $\begin{array}{l}\text { "The consultation with the CEC facilitated an adequate } \\
\text { decision-making by the health care team". Likert scale\# }\end{array}$ \\
\hline $\begin{array}{l}\text { Facilitated an adequate decision } \\
\text { implementation }\end{array}$ & Ordinal categorical & $\begin{array}{l}\text { "The consultation with the CEC facilitated an adequate } \\
\text { decision implementation by the health care team (either } \\
\text { decisions made prior to the consultation with the CEC } \\
\text { or decisions that were or were not consistent with those } \\
\text { suggested by the CEC)". Likert scale* }\end{array}$ \\
\hline It changed their opinions & Ordinal categorical & $\begin{array}{l}\text { "Extent to which the consultation with the CEC } \\
\text { changed your opinion about the case". } \\
\text { Likert scale* }\end{array}$ \\
\hline It worsened the situation & Ordinal categorical & $\begin{array}{l}\text { "The consultation with the CEC worsened the } \\
\text { situation". Likert scale* }\end{array}$ \\
\hline Positive experience & Ordinal categorical & $\begin{array}{l}\text { "The consultation with the CEC was an overall positive } \\
\text { experience". Likert scale\# }\end{array}$ \\
\hline Legal questions & Ordinal categorical & $\begin{array}{l}\text { "The consultation with the CEC helped to clear legal } \\
\text { questions". Likert scale* }\end{array}$ \\
\hline Competence & Ordinal categorical & $\begin{array}{l}\text { "The consultation with the CEC increased your } \\
\text { competence to approach difficult cases". } \\
\text { Likert scale* }\end{array}$ \\
\hline
\end{tabular}

CEC: clinical ethics committee.

\#Descriptors 1 to 5:1) Strongly disagree, 2) disagree, 3) neither agree nor disagree, 4) agree, 5) strongly agree.

${ }^{*}$ Descriptors 1 to 5: 1) Not at all, 2) very little, 3) partially, 4) almost completely, 5) completely.

For analysis purposes, the answers in the ends of the Likert scale were categorized into positive and negative and the answers in the central category, into partial. 